\title{
Comparing clinical course and outcomes of hospitalized pregnant with non-pregnant women with COVID-19 in Wuhan, China: a case-controlled study
}

\author{
Xiaoxin Zheng ${ }^{1}$, Yiyu He ${ }^{1}$, Fujin Shen ${ }^{1}$, Hua Liang ${ }^{1}$, Guo Hou ${ }^{1}$, Ying Wen ${ }^{1}$, Zhishui \\ Zheng ${ }^{1}$, Jun $\mathrm{Li}^{1}$, Xiaoyan $\mathrm{Li}^{1}$, and Xuejun Jiang ${ }^{1}$ \\ ${ }^{1}$ Affiliation not available
}

August 23, 2020

\begin{abstract}
Objective: To compare the clinical course and outcomes of hospitalized pregnant and non-pregnant patients with coronavirus disease 2019 (COVID-19). Design: Retrospective, single centre and case-control study. Setting: Renmin Hospital of Wuhan University, Wuhan, Hubei province, China Population: SARS-CoV-2-infected hospitalized 31 pregnant and 124 non-pregnant patients diagnosed between 1 January 1 and 7 May, 2020; final date of follow-up was Jul 8, 2020. Main outcomes and measures: Demographic, clinical, laboratory, radiological, treatments and outcomes were collected, analyzed and compared between the two groups. All neonates received detection for SARS-CoV-2. Results: Pregnant patients had higher leucocytes, neutrophil counts, C-reactive protein and lactate dehydrogenase level, but lower lymphocyte counts. More pregnant patients received antibiotic, corticosteroids and oxygen support. All seventeen neonates had negative results of severe acute respiratory syndrome coronavirus (SARS-CoV-2) without complications. All 31 pregnant and 124 non-pregnant patients, with similar clinical symptoms, intensive care unit admission and complications, had been discharged. Conclusion: Pregnant patients might have more obvious inflammatory response, cellular immune deficiency and potential tissue necrosis, but similar clinical manifestations and outcomes as compared with the non-pregnant patients. No evidence of neonatal infections and complications had been shown in this study. Timely and active management may be beneficial for improving the outcomes of pregnant women with COVID-19 and the neonates. Keywords: Coronavirus Disease 2019; COVID-19; Severe Acute Respiratory Syndrome Coronavirus 2; SARS-CoV-2; Pregnant; Non-Pregnant. Tweetable abstract: Pregnant women had more obvious inflammatory response, cellular immune deficiency and potential tissue necrosis, but similar clinical manifestations and outcomes.
\end{abstract}

\section{Introduction}

A crisis like the COVID-19 pandemic since last December, is a major public health event that leads to significant uncertainty. It is caused by the severe acute respiratory syndrome coronavirus 2 (SARS-CoV2 ), which is a distinct clade from the beta coronaviruses associated with human severe acute respiratory syndrome (SARS) and Middle East respiratory syndrome (MERS) ${ }^{1}$. It has infected more than 6.5 million people, claiming over 383 thousands lives in 207 countries and 5 continents as of Jun 2020. The number of COVID-19 infected pregnant women is also increasing. There is legitimate concern, however, that pregnant women might have a different disease course and outcomes, due to the physiological changes in respiratory and immunological systems.

At present, scarce data has compared the difference of the clinical characteristics of pregnant with nonpregnant patients with COVID-19 based on the data from systematic comparisons between infected pregnant and non-pregnant women. This retrospective, single-center and case-control study systematically compared the clinical course and outcomes of pregnant patients with control cases confirmed to have SARS-CoV-2 infection, and also offered some details of drug therapies of pregnant patients from the view of clinical 
practice. We hope our study findings will provide some novel and valuable information for clinicians under the COVID-19 pandemic and possibly improve the clinical outcomes of infected pregnant women.

\section{Methods}

\section{Study Design and Participants}

Renmin Hospital of Wuhan University, located in Wuhan, Hubei Province, is one of the major teaching hospitals and is responsible for the treatments for COVID-19 assigned by the Chinese government. For this retrospective, single-center, case-controlled study, all patients with COVID-19 were diagnosed according to World Health Organization interim guidance ${ }^{2}$ and were admitted centrally to the hospital from all of Wuhan without selectivity from Jan 1 to May 7, 2020; final date of follow-up was Jul 8. Thirty-seven pregnant women were infected, and 6 were excluded because they were not matched. One pregnant woman received inducing abortion before admission. Two were diagnosed as ectopic pregnancy and they received surgery soon after hospitalization, while four were excluded because of data missing. Clinical characteristics and outcomes of the remaining 31 pregnant patients were compared with another historical cohort of matched non-pregnant COVID-19 patients over the same study period (ratio: 1:4). They were matched with respect to sex, age, timing of contacting COVID-19, underlying illness and residence in Wuhan. This study was approved by the ethics committee of Renmin Hospital (No. WDRM2020-K141). Written informed consent was waived by the Ethics Commission of Renmin hospital for emerging infectious diseases.

\section{Procedures}

Clinical characteristics and outcomes data were obtained with standardized data collection forms from patients' medical records. Information recorded included demographic data, medical history, underlying comorbidities, symptoms, laboratory findings, chest computed tomographic (CT) scans, treatment measures and outcomes. The durations from onset of COVID-19 to hospital admission were recorded. The data were reviewed by a trained team of physicians. Acute kidney injury was identified according to the Kidney Disease: Improving Global Outcomes definition ${ }^{3}$. Acute liver injury, defined as either alanine aminotransferase or aspartate aminotransferase greater than three times the upper limit of normal ${ }^{4}$. Acute respiratory distress syndrome (ARDS) was diagnosed according to the Berlin Definition ${ }^{5}$.

Laboratory confirmation of SARS-CoV-2 infection was done at Renmin Hospital. Nasopharyngeal swabs specimens from the upper respiratory tract that were obtained from all patients at admission were maintained in viral transport medium. SARS-CoV-2 infection was confirmed by real-time RT-PCR using the same protocol as described previously ${ }^{6}$.All patients were given chest CT examinations.

\section{Outcomes}

We compared demographics, comorbidities, signs and symptoms on admission, laboratory results, chest CT scan findings, treatments received for COVID-19, and clinical outcomes of both pregnant and non-pregnant groups.

\section{Statistical analysis}

Continuous variables were expressed as median (25\% percentile, $75 \%$ percentile) and compared with MannWhitney U test; categorical variables were expressed as number (constituent ratio) and compared with $\chi^{2}$ test, continuity correction $\chi^{2}$ test or Fisher's exact test between pregnant and none-pregnant groups. A two-sided $\alpha$ of less than 0.05 was considered statistically significant. Statistical analyses were done using the SAS software, version 9.4, unless otherwise indicated.

\section{Results}

\section{Demographics and Characteristics}

By Jul 8, 2020, 31 pregnant and 124 non-pregnant patients with COVID-19 were included in this study. Eleven of the 31 patients were primiparous and 20 were multiparous, 8 were in the first trimester and the other 23 ones were in late second and third trimester $(26-32$ weeks). The mean age in both pregnant group 
and non-pregnant group was 30.0 years (IQR [27.0, 32.0] and [28.0, 34.0], respectively; Table 1) and mean gestational age of pregnant women was 35 weeks plus 5 days (IQR [18 weeks plus 3 days, 39 weeks plus 1 days]) at admission. All of the 17 neonates had negative COVID-19 (Apgar score [1 min] $>8$ and Apgar score $[5 \mathrm{~min}]>9$, without complications).

The comorbidities and symptoms of the two groups were compared inTable $\mathbf{1}$. No significant difference of underlying medical diseases could be found between the two groups. Of the 155 patients, $33(21.3 \%)$ had 1 or more coexisting medical conditions. Anemia (29 [18.7\%]) was the most common coexisting condition. Pregnancy had no discernible impact on the presentation pattern of COVID-19. Common symptoms at onset of illness were fever (74 [47.7\%]) and cough / haemoptysis (71 [45.8\%]); less common symptoms were fatigue / myalgia (42 [27.1\%]), anorexia (34 [21.9\%]), dyspnoea (23 [14.8\%]), pharyngalgia (19 [12.3\%]) and abdominal pain (11 [7.1\%]). The median durations of pregnant group and non-pregnant group from illness onset to hospital admission were 5 days (IQR 2.5, 10) and 8 days (IQR 5,13 ), respectively.

\section{Laboratory Findings}

Laboratory findings were shown in Table 2 . During hospitalization, leucocytes counts, neutrophil counts and C-reactive protein were higher (median leucocytes counts, $8.0 \times 109 / \mathrm{L}$ [IQR 6.5, 11.4]; median neutrophil counts, $6.2 \times 109 / \mathrm{L}$ [IQR 4.7, 8.7]; median C-reactive protein level, $17.7 \mathrm{mg} / \mathrm{L}$ [IQR 3.5, 27.3]), while lymphocyte counts were lower (median lymphocyte counts, $1.3 \times 109 / \mathrm{L}$ [IQR 1.1, 1.6]) in pregnant patients than non-pregnant cases (median leucocytes counts, $5.6 \times 109 / \mathrm{L}$ [IQR 4.6, 6.4], $\mathrm{P}<0.001$; median neutrophil counts, $3.1 \times 109 / \mathrm{L}$ [IQR 2.5, 3.9], P < 0.001; median lymphocyte counts, $1.8 \times 109 / \mathrm{L}$ [IQR 1.4, 2.1], P $<0.001$; median C-reactive protein level, $0.5 \mathrm{mg} / \mathrm{L}$ [IQR 0.5, 0.5], $\mathrm{P}<0.001$ ). There was a trend of a more obvious fall in hemoglobin level in pregnant women (median hemoglobin level, $117 \mathrm{~g} / \mathrm{L}$ [IQR 105.0, 122.0]) compared with that in contrast cases (median hemoglobin level, $126 \mathrm{~g} / \mathrm{L}$ [IQR 117.0, 132.3], $\mathrm{P}<$ 0.001). Levels of lactate dehydrogenase were increased in 11 (7.9\%) of 140 patients, including 4 of $28(14.3 \%)$ pregnant women and 7 of $112(6.3 \%)$ non-pregnant women. There was no statistical difference in the level of alanine aminotransferase and aspartate aminotransferase between the two groups. Hypersensitive troponin I located in the normal range in pregnant patients. All the 155 patients had chest CT scan, $109(70.3 \%)$ had bilateral involvement of patchy shadows or ground glass opacity. No significant difference of abnormalities presentation pattern of CT images could be observed between these two groups.

\section{Treatments and Outcomes}

Table 3 showed comparing of ICU admission, the complication rates, treatments, requirement of oxygen support, and clinical outcomes between two groups. There were no ICU admissions and no complications of ARDS, acute renal injury and acute liver injury for all the pregnant throughout the study period, as compared with $4.0 \%$ ICU admission rate $(\mathrm{P}=0.584), 0.8 \%$ ARDS $(\mathrm{P}=1.000), 0.8 \%$ acute renal injury $(\mathrm{P}=1.000)$ and $3.2 \%$ acute liver injury $(\mathrm{P}=0.584)$ in the 124 non-pregnant patients.

One hundred and thirty-two patients $(85.2 \%)$ received antiviral therapy, including oseltamivir, arbidol hydrochloride, ribavirin and peramivir. Treatment regimens of antiviral therapy were similar between the two groups $(\mathrm{P}=0.955)$. Ninety-four $(60.6 \%)$ were administered with empirical antibiotic treatment, $27(87.1 \%)$ pregnant patients and $67(54.0 \%)$ non-pregnant patients were given antibiotic treatments respectively $(\mathrm{P}=$ 0.001). For 31 pregnant patients, $10(37 \%)$ were treated with a single antibiotic and 17 patients (63\%) were given combination therapy. The antibiotics used were cefoperazone sodium tazobactam sodium, ornidazole, meropenem, azithromycin, meropenem and cefathiamidine. 43 (27.7\%) patients were given systematic corticosteroids, fifteen of $31(48 \%)$ pregnant women were treated with corticosteroid after caesarean section, as compared with $20(16.1 \%)$ in non-pregnant patients $(\mathrm{P}<0.001)$. Also, $32(20.6 \%)$ patients received immunoglobulin therapy. More details of treatment regimens of pregnant women could be found in the supplement (Table S1). Seventy-one percent of patients (71\%) in the pregnant group needed mask and nasal cannula, whereas only $27.4 \%$ in the non-pregnant women required mask and nasal cannula $(\mathrm{P}<0.001)$. Non-invasive ventilation or high-flow nasal cannula was required in $2(1.6 \%)$ non-pregnant patients. One case in non-pregnant group needed invasive mechanical ventilation ECMO, this difference did not reach 
statistical significance.

At the end of follow-up (Jul 8, 2020), all patients in both groups had been discharged from Renmin hospital per the following discharge criteria: abatement of fever for more than 3 days, with improvement of chest radiographic evidence and viral clearance in respiratory samples from upper respiratory tract (negative twice in a row, sampling interval [?]24 h). The pregnant women required a little longer hospital stay than the non-pregnant group without statistical significance (13.0 days [IQR 9.0, 24.0] vs 9.0 days [IQR 8.0, 15.8], P $=0.062$ ).

\section{Discussion}

\section{Main findings}

At present, scarce comparison data from a control study had answer the question directly: whether pregnancy has impact on clinical course and outcomes of pregnant women confirmed to have SARS-CoV-2 infection or not. In this descriptive, single-center, case-controlled study, we get a comprehensive understanding that: (1) the pregnant patients had higher leucocytes, neutrophil counts, C-reactive protein and lactate dehydrogenase level, but lower lymphocyte counts; (2) pregnancy had no discernible impact on clinical symptoms, intensive care unit admission and complications (including ARDS, acute renal injury, acute liver injury and urinary tract infection); (3) more pregnant patients received antibiotic, corticosteroids and oxygen support; (4) all the 17 neonates tested for SARS-CoV-2 had negative results without complications; (5) all the 31 pregnant and 124 non-pregnant patients had been discharged with no deaths.

\section{Interpretation}

Common symptoms at onset of COVID-19 of pregnant women were fever, cough and abdominal pain, and the less common symptoms were chills, dyspnoea, chest pain and pharyngalgia. However, some patients presented initially with atypical symptoms, such as diarrhea and rhinobyon. The most significant laboratory abnormalities observed in pregnant group were depressed lymphocytes counts, increased leucocytes and neutrophil counts, and elevated C-reactive protein level compared with those in non-pregnant group (all $\mathrm{P}<0.001$, Table 2). These abnormalities suggest that SARS-CoV-19 infection in pregnant women may be associated with cellular immune deficiency and inflammation response (may resulted in cytokine storm) induced by virus. Meanwhile, physiological haemodilution in pregnancy lowers the hemoglobin level of pregnant women, as reflected in the difference of hemoglobin level between the two groups. A further drop in hemoglobin level might jeopardise the stressed oxygen carrying capacity of mother, adding further risk to pregnant COVID-19 patients. Additionally, a higher level of lactate dehydrogenase at presentation had been associated with potential severity among pneumonia patients in $\operatorname{most}^{7}$, but not all, case series ${ }^{8}$. Likewise, a higher lactate dehydrogenase level was found in our pregnant group, reflecting tissue necrosis related to immune hyperactivity in COVID-19. The presence of such adverse outcome predictor may reflect the severity of the disease course in pregnancy.

Currently, the approach to this disease is to control the source of infection; use of personal protection precaution to reduce the risk of transmission; and early diagnosis, isolation, and supportive treatments for affected patients. Until now, no specific treatment has been proven to be effective for coronavirus infection except for meticulous supportive care ${ }^{9}$. In our study, most pregnant patients were treated with arbidol and oseltamivir (24 of 31 patients, $77.4 \%$ ). Although arbidol and other antiviral drugs have been used in the clinical treatment of patients with COVID-19, no data of their safety and efficacy as COVID-19 treatments have been published. The experience gained from previous antiviral pneumonia (eg. SARS and MERS) is also limited ${ }^{10-12}$. More pregnant patients received antibacterial agents and corticosteroids in this study, as compared with non-pregnant patients (all P [?] 0.001; Table 3 and online supplement, Table S1). Timely use of antibiotics to prevent secondary bacterial infections and strengthen immune support treatment can reduce complications and mortality, so antibiotics were used routinely after operation ${ }^{13}$. Corticosteroids should not be routinely given systemically, unless for possible benefit by reducing inflammatory-induced lung injury, according to WHO interim guidance ${ }^{14}$. Additionally, the use of large doses of corticosteroids during pregnancy might lead to fetal malformation in previous study ${ }^{15}$. Among our two groups of 155 
laboratory-confirmed patients with SARS-CoV-19 infection, corticosteroids were given to very few nonpregnant women (16.1\%), and low dose of corticosteroids were given to 23 pregnant patients $(74.2 \%$, Table 3 and online supplement, Table S1). Thus far, no complications related to the steroids have been recorded in the pregnant women, mothers and neonates in our study. Further evidence is urgently needed to assess their safety. As is known to us, total lung capacity of pregnant women decreases towards term. There is also a decrease in both residual volume and expiratory volume in pregnant women, resulting in a $9.5 \%$ to $25 \%$ drop in functional residual capacity. Moreover, there is a $20 \%$ increase in oxygen demand in pregnancy ${ }^{16}$. This might explain why more pregnant patients required oxygen support in this study (Table 3 ).

Because of alterations in hormone levels and decreased lung volumes caused by increases in uterus size during pregnancy, patients might have a more rapid clinical deterioration. In this study, we have presented 31 cases of COVID-19 in pregnancy and 124 control cases with similar outcomes, including 17 newborns with negative COVID-19. There were no ICU admissions and no complications of ARDS, acute renal injury and acute liver injury for all the pregnant throughout the study period. All of the 155 patients have been discharged as of Jul 8, 2020, the hospital stay of pregnant patients was 13 days (IQR, 9.0-24.0). These results are different from those former pneumonias (eg. SARS, MERS, H1N1, et al) ${ }^{17}$, 18 , which stated that infected pregnant patients had wore outcomes. This might be associated with: First, different pathogenicity among these human coronaviruses. For example, the mortality rate of SARS infection is $10 \%^{19}$, and the mortality rate of SARS in pregnant women was $25 \%^{20}$, while the mortality rate of patients with COVID-19 is about $1.4 \%^{21}$. Second, COVID-19 pneumonia in pregnancy is a complicated clinical scenario, a multidisciplinary team of medical personnel from Renmin Hospital of Wuhan University participated in the whole procedure of caring these patients comprehensively and timely (the median durations of pregnant women from illness onset to hospital admission were 5 days). This team, including obstetrics, internal medicine, paediatrics, infectious diseases, anaesthesia, psychology, and infection control, has played a positive role.

\section{Strengths and limitations}

This case-control study is the first to systematically compared clinical course and outcomes of hospitalized pregnant patients with non-pregnant patients with COVID-19. It was conducted at Renmin Hospital of Wuhan University in Wuhan, China, from January 1 to May 7, 2020; final date of follow-up was Jul 8, 2020. This hospital is one of the major teaching hospitals and is responsible for the treatments for COVID-19 assigned by the Chinese government under scientific guidance. The research duration covered the major process of COVID-19 epidemic in Wuhan. All of those ensured adequate number of hospitalized cases and comparability of data. Our data were collected using a standardized customized data collection forms from patients' medical records by a trained team of physicians, and verified independently by 2 investigators. Our study has some limitations. First, though all the cases were selected at random, few critical and serious cases were included in this study, limiting the clinical implications. Second, all patients in this study were from the Renmin Hospital of Wuhan University, there may be different clinical characteristics in different areas due to differences in race, policies, culture and medical conditions, so the results should be treated with caution. Third, neonates were only evaluated at birth, continued observations of the natural history of the neonates and infants are needed.

\section{Conclusion}

In our study, SARS-CoV-2 infected pregnant patients experienced more obvious inflammatory response, cellular immune deficiency and potential tissue necrosis. These may reflect the potential severity of the disease course in pregnancy, but the clinical outcomes are similar between the two groups. No evidence of neonatal infections and complications had been shown in this study. Timely, intensive, active management and surveillance activities from multidisciplinary medical cooperation may be beneficial for improving the outcomes of pregnant women confirmed to have SARS-CoV-2 infection and the neonates.

\section{Acknowledgements}

We acknowledge all medical staff involved in the diagnosis and treatment of patients with COVID-19 in Wuhan. We thank Xiuquan Lin, M.D.,from Fujian Provincial Center for Disease Control and Prevention, 
Fuzhou 211 Project Data Analysis Service Co., Ltd. and Yi Sun, M.D., Shuna Huang M.M., from School of Public Health, Fujian Medical University, for data collation and statistical analysis. They were not compensated for their contributions.

\section{Disclosure of Interests}

The authors report no conflict of interest. Completed disclosure of interest forms are available to view online as supporting information.

\section{Contribution to Authorship}

XJJ had full access to all the data in the study and take responsibility for the integrity of the data and the accuracy of the data analysis. XXZ and YYH contributed to the work equally. XXZ, YYH, FJS and HL made substantial contributions to study concept and design. FJS, HL, GH, YW, ZSZ, JL and XYL were responsible for the acquisition, analysis, or interpretation of data, XXZ, XYL and XJJ were responsible for statistical analysis. XXZ, YYH and XJJ were in charge of the manuscript draft, XJJ made substantial revisions to the manuscript.

\section{Detail of Ethics Approval}

This study was approved by the ethics committee of Renmin Hospital of Wuhan University (ID: WDRM2020K141). Written informed consent was waived by the Ethics Commission of Renmin hospital for emerging infectious diseases.

\section{Funding}

This work was supported by grants of National Natural Science Foundation of China (No. 81800431 and No. 81800444) and the Natural Science Foundation of Hubei Province (No. 2018CFB415).

\section{Data Sharing}

The data used and analyzed during the current study are available from the corresponding author on reasonable request.

\section{References}

1. Zhu N, Zhang D, Wang W, Li X, Yang B, Song J, et al. A novel coronavirus from patients with pneumonia in china, 2019. N Engl J Med. 2020;382:727-733.

2. World Health Organization. Clinical management of severe acute respiratory infection when novel coronavirus (nCoV) infection is suspected: interim guidance. Published January 28 AJ, 2020. https://www.who.int/publications-detail/clinical-management-of-severe-acute-respiratory-infectionwhen-novel- coronavirus-(ncov)-infection-is-suspected.

3. Khwaja A. Kdigo clinical practice guidelines for acute kidney injury. Nephron Clin Pract. 2012;120:c179184.

4. Duan ZP, Chen Y, Zhang J, Zhao J, Lang ZW, Meng FK, et al. Clinical characteristics and mechanism of liver injury in patients with severe acute respiratory syndrome. Chin J Hepatol. 2003;11:493-496.

5. Ranieri VM, Rubenfeld GD, Thompson BT, Ferguson ND, Caldwell E, Fan E, et al. Acute respiratory distress syndrome: The berlin definition. Jama. 2012;307:2526-2533.

6. Huang C, Wang Y, Li X, Ren L, Zhao J, Hu Y, et al. Clinical features of patients infected with 2019 novel coronavirus in wuhan, china. Lancet. 2020;395:497-506.

7. Chim SS, Tsui SK, Chan KC, Au TC, Hung EC, Tong YK, et al. Genomic characterisation of the severe acute respiratory syndrome coronavirus of amoy gardens outbreak in hong kong. Lancet. 2003;362:1807-1808.

8. Booth CM, Matukas LM, Tomlinson GA, Rachlis AR, Rose DB, Dwosh HA, et al. Clinical features and short-term outcomes of 144 patients with sars in the greater toronto area. JAMA. 2003;289:2801-2809. 
9. de Wit E, van Doremalen N, Falzarano D, Munster VJ, et al. Sars and mers: Recent insights into emerging coronaviruses. Nat Rev Microbiol. 2016;14:523-534.

10. Sheahan TP, Sims AC, Leist SR, Schafer A, Won J, Brown AJ, et al. Comparative therapeutic efficacy of remdesivir and combination lopinavir, ritonavir, and interferon beta against mers-cov. Nat Commun. 2020;11:222.

11. Chu CM, Cheng VC, Hung IF, Wong MM, Chan KH, Chan KS, et al. Role of lopinavir/ritonavir in the treatment of sars: Initial virological and clinical findings. Thorax. 2004;59:252-256.

12. Arabi YM, Alothman A, Balkhy HH, Al-Dawood A, AlJohani S, Al Harbi S, et al. Treatment of middle east respiratory syndrome with a combination of lopinavir-ritonavir and interferon-beta1b (miracle trial): Study protocol for a randomized controlled trial. Trials. 2018;19:81.

13. Chen N, Zhou M, Dong X, Qu J, Gong F, Han Y, et al. Epidemiological and clinical characteristics of 99 cases of 2019 novel coronavirus pneumonia in wuhan, china: A descriptive study. Lancet. 2020;395:507-513.

14. WHO. Clinical management of severe acute respiratory infection when novel coronavirus (nCoV) infection is suspected. Jan 11 hwwii-p-dc-, management-of-severe-acute-respiratory-infection-when-novel-coronavirus(ncov)-infection-is-suspected. Accessed Jan 19.

15. Tegethoff M, Pryce C, Meinlschmidt G. Effects of intrauterine exposure to synthetic glucocorticoids on fetal, newborn, and infant hypothalamic-pituitary-adrenal axis function in humans: A systematic review. Endocr Rev. 2009;30:753-789.

16. Alaily AB, Carrol KB. Pulmonary ventilation in pregnancy. Brit J Obstet Gynaec. 1978;85:518-524.

17. Lam CM, Wong SF, Leung TN, Chow KM, Yu WC, Wong TY, et al. A case-controlled study comparing clinical course and outcomes of pregnant and non-pregnant women with severe acute respiratory syndrome. BJOG. 2004;111:771-774.

18. Rasmussen SA, Smulian JC, Lednicky JA, Wen TS, Jamieson DJ, et al. Coronavirus disease 2019 (covid-19) and pregnancy: What obstetricians need to know. Am J Obstet Gynecol. 2020;222:415-426.

19. WHO. Summary of probable SARS cases with onset of illness from 1 November 2002 to 31 July 2003. https://www.who.int/csr/sars/country/table2004_04_21/en/. Accessed Feb 12, 2020.

20. Wong SF, Chow KM, Leung TN, Ng WF, Ng TK, Shek CC, et al. Pregnancy and perinatal outcomes of women with severe acute respiratory syndrome. Am J Obstet Gynecol. 2004;191:292-297.

21. Guan WJ, Ni ZY, Hu Y, Liang WH, Ou CQ, He JX, et al. Clinical characteristics of coronavirus disease 2019 in china. N Engl J Med. 2020;382:1708-1720.

Table 1. Demographics and Baseline Characteristics of Pregnant and Non-Pregnant Patients With COVID-19

\begin{tabular}{lll}
\hline & & Total $(\mathrm{N}=15$ \\
\hline Age, years & Age, years & $30.0(28.0,34$. \\
Gestational age, weeks + days & Gestational age, weeks & NA days \\
Comorbidities & Comorbidities & $29(18.7 \%)$ \\
Anemia & Anemia & $2(1.3 \%)$ \\
Chronic kidney disease & Chronic kidney disease & $2(1.3 \%)$ \\
Hypertension & Hypertension & $1(0.6 \%)$ \\
Atrial septal defect & Atrial septal defect & $1(0.6 \%)$ \\
Type 2 diabetes & Type 2 diabetes & $1(0.6 \%)$ \\
Endocrine system disease & Endocrine system disease & $1(0.6 \%)$
\end{tabular}




\begin{tabular}{lll}
\hline & & Total $(\mathrm{N}=15$ \\
\hline Fever & Fever & $74(47.7 \%)$ \\
Chills & Chills & $5(3.2 \%)$ \\
Cough / Haemoptysis & Cough / Haemoptysis & $71(45.8 \%)$ \\
Dyspnoea & Dyspnoea & $23(14.8 \%)$ \\
Abdominal pain & Abdominal pain & $11(7.1 \%)$ \\
Chest pain / Chest distress & Chest pain / Chest distress & $26(16.8 \%)$ \\
Pharyngalgia & Pharyngalgia & $19(12.3 \%)$ \\
Anorexia & Anorexia & $34(21.9 \%)$ \\
Rhinobyon / Rhinorrhoea & Rhinobyon / Rhinorrhoea & $8(5.2 \%)$ \\
Diarrhea & Diarrhea & $7(4.5 \%)$ \\
Dizziness / Headache & Dizziness / Headache & $9(5.8 \%)$ \\
Fatigue / Myalgia & Fatigue / Myalgia & $42(27.1 \%)$ \\
Palpitations & Palpitations & $4(2.6 \%)$ \\
Nausea / Vomiting & Nausea / Vomiting & $2(1.3 \%)$ \\
Days from illness onset to, Hospital admission, days & Days from illness onset to, Hospital admission, days & $7(4.75,13)$ \\
Systolic pressure, mmHg & $118(112,123)$ & $118(112,123)$ \\
Respiratory rate $>24$ bpm & $25(16.1 \%)$ & $25(16.1 \%)$ \\
\hline
\end{tabular}

Data are median (IQR) or n (\%). NA, not applicable; bpm, beats per minute; $\mathrm{P}$ values indicate differences between Pregnant COVID-19 and non- Pregnant COVID-19 patients are from $\chi^{2}$ test, Fisher's exact test, or Mann-Whitney $\mathrm{U}$ test. $\mathrm{P}<0.05$ was considered statistically significant.

Table 2. Laboratory Findings of Pregnant and Non-Pregnant Patients With COVID-19 on Admission to Hospital

\begin{tabular}{|c|c|c|c|c|c|}
\hline & Normal Range & Total $(\mathrm{N}=155)$ & $\begin{array}{l}\text { Pregnant } \\
\text { COVID-19 } \\
\text { patients }(\mathrm{n}=31)\end{array}$ & $\begin{array}{l}\text { Non-Pregnant } \\
\text { COVID-19 } \\
\text { patients }(\mathrm{n}= \\
124)\end{array}$ & P Value \\
\hline $\begin{array}{l}\text { Leucocytes } \\
\text { counts, } \times \\
109 / \mathrm{L}\end{array}$ & $4-10$ & $5.9(5.1,7.2)$ & $8.0(6.5,11.4)$ & $5.6(4.6,6.4)$ & $<.001$ \\
\hline$<4$ & $\mathrm{NA}$ & $10 / 147(6.8 \%)$ & $1 / 31(3.2 \%)$ & $9 / 116(7.8 \%)$ & $<.001$ \\
\hline $4-10$ & NA & $\begin{array}{l}124 / 147 \\
(84.4 \%)\end{array}$ & $21 / 31(67.7 \%)$ & $\begin{array}{l}103 / 116 \\
(88.8 \%)\end{array}$ & $\ldots$ \\
\hline$>10$ & $\mathrm{NA}$ & $13 / 147(8.8 \%)$ & $9 / 31(29.0 \%)$ & $4 / 116(3.4 \%)$ & $\ldots$ \\
\hline $\begin{array}{l}\text { Neutrophil } \\
\text { counts, } \times \\
109 / \mathrm{L}\end{array}$ & $1.8-6.3$ & $3.4(2.7,4.7)$ & $6.2(4.7,8.7)$ & $3.1(2.5,3.9)$ & $<.001$ \\
\hline $\begin{array}{l}\text { Lymphocyte } \\
\text { counts, } \times \\
109 / \mathrm{L}\end{array}$ & $1.0-3.2$ & $1.7(1.3,2.0)$ & $1.3(1.1,1.6)$ & $1.8(1.4,2.1)$ & $<.001$ \\
\hline$<1 \cdot 0$ & $\mathrm{NA}$ & $11 / 147(7.5 \%)$ & $4 / 31(12.9 \%)$ & $7 / 116(6.0 \%)$ & .364 \\
\hline$[?] 1 \cdot 0$ & NA & $\begin{array}{l}136 / 147 \\
(92.5 \%)\end{array}$ & $27 / 31(87.1 \%)$ & $\begin{array}{l}109 / 116 \\
(94.0 \%)\end{array}$ & $\cdots$ \\
\hline $\begin{array}{l}\text { Monocyte, } \times \\
\text { 109/L }\end{array}$ & $0.1-0.6$ & $0.4(0.3,0.5)$ & $0.4(0.3,0.6)$ & $0.4(0.3,0.5)$ & .022 \\
\hline
\end{tabular}




\begin{tabular}{|c|c|c|c|c|c|}
\hline & Normal Range & Total $(\mathrm{N}=155)$ & $\begin{array}{l}\text { Pregnant } \\
\text { COVID-19 } \\
\text { patients }(\mathrm{n}=31)\end{array}$ & $\begin{array}{l}\text { Non-Pregnant } \\
\text { COVID-19 } \\
\text { patients }(\mathrm{n}= \\
124)\end{array}$ & $\mathrm{P}$ Value \\
\hline $\begin{array}{l}\text { Platelet } \\
\text { counts, } \times \\
109 / \mathrm{L}\end{array}$ & $125-350$ & $\begin{array}{l}226.5(188.5 \\
267.5)\end{array}$ & $\begin{array}{l}233.2(194.0 \\
259.5)\end{array}$ & $\begin{array}{l}226.0(188.2 \\
270.8)\end{array}$ & .716 \\
\hline$<100$ & NA & $2 / 147(1.4 \%)$ & 0 & $2 / 116(1.7 \%)$ & 1.000 \\
\hline$[?] 100$ & NA & $\begin{array}{l}145 / 147 \\
(98.6 \%)\end{array}$ & $\begin{array}{l}31 / 31 \\
(100.0 \%)\end{array}$ & $\begin{array}{l}114 / 116 \\
(98.3 \%)\end{array}$ & $\ldots$ \\
\hline $\begin{array}{l}\text { Hemoglobin, } \\
\text { g/L }\end{array}$ & $115-150$ & $\begin{array}{l}123.0(115.7 \\
131.0)\end{array}$ & $\begin{array}{l}117.0 \\
122.0)\end{array}$ & $\begin{array}{l}126.0 \\
132.3)\end{array}$ & $<.001$ \\
\hline Albumin, g/L & $40-55$ & $\begin{array}{l}41.7(38.6 \\
43.2)\end{array}$ & $\begin{array}{l}37.2(35.2, \\
38.8)\end{array}$ & $\begin{array}{l}42.1(40.5 \\
43.7)\end{array}$ & $<.001$ \\
\hline $\begin{array}{l}\text { Creatine } \\
\text { kinase, U/L }\end{array}$ & $<171$ & $\begin{array}{l}42.3(31.0 \\
57.7)\end{array}$ & $\begin{array}{l}33.7(20.2 \\
67.5)\end{array}$ & $\begin{array}{l}42.8(33.0 \\
56.2)\end{array}$ & .312 \\
\hline [?]185 & NA & $\begin{array}{l}140 / 140 \\
(100.0 \%)\end{array}$ & $\begin{array}{l}28 / 28 \\
(100.0 \%)\end{array}$ & $\begin{array}{l}112 / 112 \\
(100.0 \%)\end{array}$ & $\ldots$ \\
\hline$>185$ & NA & 0 & 0 & 0 & $\ldots$ \\
\hline $\begin{array}{l}\text { Lactate dehy- } \\
\text { drogenase, } \\
\text { U/L }\end{array}$ & $125-245$ & $\begin{array}{l}179.0(146.0, \\
204.2)\end{array}$ & $\begin{array}{l}202.5(181.3 \\
220.5)\end{array}$ & $\begin{array}{l}168.5(140.7 \\
199.0)\end{array}$ & $<.001$ \\
\hline$[?] 245$ & NA & $\begin{array}{l}129 / 140 \\
(92.1 \%)\end{array}$ & $24 / 28(85.7 \%)$ & $\begin{array}{l}105 / 112 \\
(93.8 \%)\end{array}$ & .307 \\
\hline$>245$ & NA & $11 / 140(7.9 \%)$ & $4 / 28(14.3 \%)$ & $7 / 112(6.3 \%)$ & $\ldots$ \\
\hline $\begin{array}{l}\text { Alanine } \\
\text { aminotrans- } \\
\text { ferase, } \\
\text { U/L }\end{array}$ & $7-40$ & $\begin{array}{l}18.6(11.3, \\
27.1)\end{array}$ & $\begin{array}{l}14.0(10.6, \\
26.1)\end{array}$ & $\begin{array}{l}19.5(12.0, \\
28.1)\end{array}$ & .137 \\
\hline $\begin{array}{l}\text { Aspartate } \\
\text { aminotrans- } \\
\text { ferase, } \\
\text { U/L }\end{array}$ & $13-40$ & $\begin{array}{l}19.0(15.2, \\
24.0)\end{array}$ & $\begin{array}{l}20.2(15.2, \\
28.0)\end{array}$ & $\begin{array}{l}19.0(15.2, \\
23.0)\end{array}$ & .434 \\
\hline$[?] 40$ & NA & $\begin{array}{l}138 / 142 \\
(97.2 \%)\end{array}$ & $\begin{array}{l}28 / 28 \\
(100.0 \%)\end{array}$ & $\begin{array}{l}110 / 114 \\
(96.5 \%)\end{array}$ & .585 \\
\hline$>40$ & NA & $4 / 142(2.8 \%)$ & 0 & $4 / 114(3.5 \%)$ & $\ldots$ \\
\hline $\begin{array}{l}\text { Total } \\
\text { bilirubin, } \\
\mathrm{mmol} / \mathrm{L}\end{array}$ & $0-23$ & $9.3(7.5,11.7)$ & $8.7(7.5,11.9)$ & $9.3(7.6,11.7)$ & .788 \\
\hline $\begin{array}{l}\text { Blood urea } \\
\text { nitrogen, } \\
\text { mmol/L }\end{array}$ & $3.1-8.8$ & $3.63(3.1,4.3)$ & $3.0(2.6,3.6)$ & $3.7(3.2,4.4)$ & $<.001$ \\
\hline $\begin{array}{l}\text { Serum } \\
\text { creatinine, } \\
\mu \mathrm{mol} / \mathrm{L}\end{array}$ & $41-81$ & $\begin{array}{l}48.0(42.0, \\
53.0)\end{array}$ & $\begin{array}{l}43.2(38.0, \\
48.7)\end{array}$ & $\begin{array}{l}49.0(42.7, \\
53.7)\end{array}$ & .003 \\
\hline$[?] 133$ & NA & $\begin{array}{l}139 / 140 \\
(99.3 \%)\end{array}$ & $\begin{array}{l}28 / 28 \\
(100.0 \%)\end{array}$ & $\begin{array}{l}111 / 112 \\
(99.1 \%)\end{array}$ & 1.000 \\
\hline$>133$ & NA & $1 / 140(0.7 \%)$ & 0 & 1/112 (0.9\%) & $\ldots$ \\
\hline $\begin{array}{l}\text { Potassium, } \\
\mathrm{mmol} / \mathrm{L}\end{array}$ & $136-147$ & $3.9(3.8,4.2)$ & $3.9(3.7,4.0)$ & $4.0(3.8,4.3)$ & .043 \\
\hline
\end{tabular}




\begin{tabular}{|c|c|c|c|c|c|}
\hline & Normal Range & Total $(\mathrm{N}=155)$ & $\begin{array}{l}\text { Pregnant } \\
\text { COVID-19 } \\
\text { patients }(\mathrm{n}=31)\end{array}$ & $\begin{array}{l}\text { Non-Pregnant } \\
\text { COVID-19 } \\
\text { patients }(\mathrm{n}= \\
124)\end{array}$ & $\mathrm{P}$ Value \\
\hline $\begin{array}{l}\text { Sodium, } \\
\mathrm{mmol} / \mathrm{L}\end{array}$ & $3.5-5.5$ & $\begin{array}{l}140.4(139.0, \\
142.0)\end{array}$ & $\begin{array}{l}140.0(138.0, \\
142.3)\end{array}$ & $\begin{array}{l}\text { 140.4 (139.0, } \\
142.0)\end{array}$ & .514 \\
\hline $\begin{array}{l}\text { C-reactive } \\
\text { protein, mg/L }\end{array}$ & $0-3$ & $0.5(0.5,6.8)$ & $17.7(3.5,27.3)$ & $0.5(0.5,0.5)^{\wedge}$ & $<.001$ \\
\hline $\begin{array}{l}\text { Procalcitonin, } \\
\mathrm{ng} / \mathrm{mL}\end{array}$ & $<0.5$ & NA & $\begin{array}{l}0.06(0.04, \\
0.09)\end{array}$ & $\mathrm{NA}^{\&}$ & $\ldots$ \\
\hline $\begin{array}{l}\text { Hypersensitive } \\
\text { troponin I, } \\
\mathrm{ng} / \mathrm{mL}\end{array}$ & $0-0.04$ & NA & $\begin{array}{l}0.006(0.006 \\
0.006)^{\wedge}\end{array}$ & $N A^{\&}$ & $\ldots$ \\
\hline $\begin{array}{l}\text { Bilateral } \\
\text { distribution of } \\
\text { patchy } \\
\text { shadows or } \\
\text { ground glass } \\
\text { opacity }\end{array}$ & NA & $\begin{array}{l}109 / 155 \\
(70.3 \%)\end{array}$ & $27 / 31(87.0 \%)$ & $\begin{array}{l}88 / 124 \\
(70.9 \%)\end{array}$ & .077 \\
\hline
\end{tabular}

Data are median (IQR) or $\mathrm{n} / \mathrm{N}(\%)$, where $\mathrm{N}$ is the total number of patients with available data. NA, not applicable; $\mathrm{P}$ values indicate differences between Pregnant COVID-19 and non- Pregnant COVID-19 patients are from $\chi^{2}$ test, Fisher's exact test, or Mann-Whitney U test. $\mathrm{P}<0.05$ was considered statistically significant. 'Results displayed as $<0.5$ or $<0.006$ were adopted as 0.5 or 0.006 for statistical analysis, respectively; ${ }^{\&}$ Data are insufficient for statistics.

Table 3. Complications. Treatments and Outcomes of Pregnant and Non-Pregnant Patients With COVID-19

\begin{tabular}{|c|c|c|c|c|}
\hline & Total $(\mathrm{N}=155)$ & $\begin{array}{l}\text { Pregnant } \\
\text { COVID-19 patients } \\
(\mathrm{n}=31)\end{array}$ & $\begin{array}{l}\text { Non-Pregnant } \\
\text { COVID-19 patients } \\
(\mathrm{n}=124)\end{array}$ & $\mathrm{P}$ Value \\
\hline $\begin{array}{l}\text { ICU admission } \\
\text { Complications }\end{array}$ & $5(3.2 \%)$ & 0 & $5(4.0 \%)$ & .584 \\
\hline ARDS & $1(0.6 \%)$ & 0 & $1(0.8 \%)$ & 1.000 \\
\hline $\begin{array}{l}\text { Acute kidney } \\
\text { injury }\end{array}$ & $1(0.6 \%)$ & 0 & $1(0.8 \%)$ & 1.000 \\
\hline Acute liver injury & $4(2.6 \%)$ & 0 & $4(3.2 \%)$ & .584 \\
\hline $\begin{array}{l}\text { Urinary tract } \\
\text { infection }\end{array}$ & $2(1.3 \%)$ & $1(3.2 \%)$ & $1(0.8 \%)$ & .361 \\
\hline $\begin{array}{l}\text { Treatments } \\
\text { Antiviral therapy }\end{array}$ & $132(85.2 \%)$ & $27(87.1 \%)$ & $105(84.7 \%)$ & .955 \\
\hline $\begin{array}{l}\text { Antibiotic } \\
\text { therapy }\end{array}$ & $94(60.6 \%)$ & $27(87.1 \%)$ & $67(54.0 \%)$ & .001 \\
\hline Corticosteroid & $43(27.7 \%)$ & $23(74.2 \%)$ & $20(16.1 \%)$ & $<.001$ \\
\hline Immunoglobulin & $32(20.6 \%)$ & $5(16.1 \%)$ & $27(21.8 \%)$ & .487 \\
\hline $\begin{array}{l}\text { Continuous renal } \\
\text { replacement } \\
\text { therapy }\end{array}$ & $1(0.6 \%)$ & 0 & $1(0.8 \%)$ & 1.000 \\
\hline $\begin{array}{l}\text { Oxygen } \\
\text { support }\end{array}$ & $56(36.1 \%)$ & $22(71.0 \%)$ & $34(27.4 \%)$ & $<.001$ \\
\hline
\end{tabular}




\begin{tabular}{lllll}
\hline & Total $(\mathrm{N}=155)$ & $\begin{array}{l}\text { Pregnant } \\
\text { COVID-19 patients } \\
(\mathrm{n}=31)\end{array}$ & $\begin{array}{l}\text { Non-Pregnant } \\
\text { COVID-19 patients } \\
(\mathrm{n}=124)\end{array}$ & P Value \\
\hline $\begin{array}{l}\text { Mask and Nasal } \\
\text { cannula }\end{array}$ & $53(34.2 \%)$ & $22(71.0 \%)$ & $31(25.0 \%)$ & $\ldots$ \\
$\begin{array}{l}\text { Non-invasive } \\
\text { ventilation or } \\
\text { high-flow nasal } \\
\text { cannula }\end{array}$ & $2(1.3 \%)$ & 0 & $2(1.6 \%)$ & $\ldots$ \\
$\begin{array}{l}\text { Invasive } \\
\text { mechanical }\end{array}$ & 0 & 0 & 0 & $\ldots$ \\
$\begin{array}{l}\text { ventilation } \\
\text { Invasive } \\
\text { mechanical } \\
\text { ventilation and }\end{array}$ & $1(0.6 \%)$ & 0 & $1(0.8 \%)$ & $\ldots$ \\
$\begin{array}{l}\text { ECMO } \\
\text { Clinical } \\
\text { outcomes }\end{array}$ & & & & \\
$\begin{array}{l}\text { Hospital stays, } \\
\text { days }\end{array}$ & $9(8.0,17.0)$ & $13(9.0,24.0)$ & $9.0(8.0,15.8)$ & \\
\begin{tabular}{l} 
Discharge \\
\hline
\end{tabular} & $155(100.0 \%)$ & $31(100.0 \%)$ & $124(100.0 \%)$ & $\ldots$ \\
\hline
\end{tabular}

Data are median (IQR) or n (\%). ICU, intensive care unit; ARDS, acute respiratory distress syndrome; DIC, disseminated intravascular coagulopathy; $\mathrm{P}$ values indicate differences between Pregnant COVID-19 and non- Pregnant COVID-19 patients are from $\chi^{2}$ test, Fisher's exact test, or Mann-Whitney U test. P < 0.05 was considered statistically significant. 